\title{
k-Generalized $\Psi$-Hilfer differential equations in Banach spaces
}

\author{
Salim Abdelkrim ${ }^{1}$, Mouffak Benchohra ${ }^{2}$, Jamal Lazreg${ }^{1}$, and Gaston NGuerekata ${ }^{3}$ \\ ${ }^{1}$ University of Djillali Liabes Sidi Bel Abbes \\ ${ }^{2}$ University of Sidi Bel Abbes \\ ${ }^{3}$ Morgan State University
}

April 3, 2021

\begin{abstract}
In this paper, we prove some existence and Ulam-Hyers-Rassias stability results for a class of initial value problem for implicit nonlinear fractional differential equations and generalized $\Psi$-Hilfer fractional derivative in Banach spaces. The results are based on fixed point theorems of Darbo and Monch associated with the technique of measure of noncompactness. Illustrative examples are the subject of the last section.
\end{abstract}

\section{Hosted file}

wileyNJD-AMA-1-1.pdf available at https://authorea.com/users/405528/articles/516479-kgeneralized-\%CF\%88-hilfer-differential-equations-in-banach-spaces 